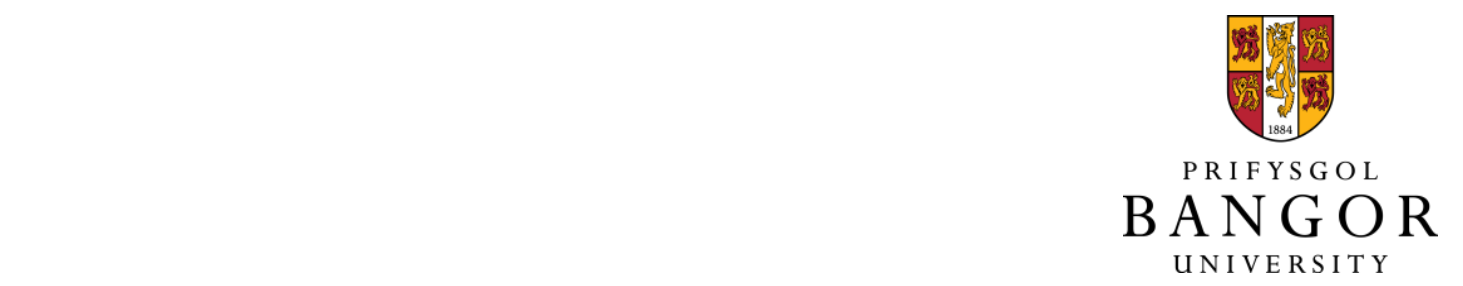

\title{
Evaluation of an intervention targeting loneliness and isolation for older
} people in North Wales

Roberts, Jennifer; Windle, Gillian

\section{Perspectives in Public Health}

DOI:

$10.1177 / 1757913919868752$

Published: 01/05/2020

Peer reviewed version

Cyswllt i'r cyhoeddiad / Link to publication

Dyfyniad o'r fersiwn a gyhoeddwyd / Citation for published version (APA):

Roberts, J., \& Windle, G. (2020). Evaluation of an intervention targeting loneliness and isolation for older people in North Wales. Perspectives in Public Health, 140(3), 153-161.

https://doi.org/10.1177/1757913919868752

\footnotetext{
Hawliau Cyffredinol / General rights

Copyright and moral rights for the publications made accessible in the public portal are retained by the authors and/or other copyright owners and it is a condition of accessing publications that users recognise and abide by the legal requirements associated with these rights.

- Users may download and print one copy of any publication from the public portal for the purpose of private study or research.

- You may not further distribute the material or use it for any profit-making activity or commercial gain

- You may freely distribute the URL identifying the publication in the public portal ?
}

Take down policy

If you believe that this document breaches copyright please contact us providing details, and we will remove access to the work immediately and investigate your claim. 
Original Research

Corresponding Author: Dr Jennifer Rhiannon Roberts

School of Health Sciences, Bangor University, Ardudwy, Normal Site, LL57 2PZ.

Email: j.roberts@bangor.ac.uk

\section{Evaluation of an intervention targeting loneliness and isolation for older people in North Wales.}

\section{Dr Jennifer Rhiannon Roberts}

School of Health Sciences, Bangor University, Ardudwy, Normal Site, LL57 2PZ.

Email: j.roberts@bangor.ac.uk

Prof Gill Windle, Bangor University

School of Health Sciences, Bangor University, Fron Heulog, LL57 2EF.

Email: g.windle@bangor.ac.uk 


\title{
Evaluation of an intervention targeting loneliness and isolation for older people in North Wales.
}

\begin{abstract}
Aims: Age Cymru, Gwynedd and Môn provided a service, Cadwyn Môn, which aimed to reduce loneliness and isolation of older people living on Anglesey, North Wales. It involved working with individuals to identify goals, beginning on a one-to-one basis, with the aim of integrating into a wider social setting. The aim of this study was evaluate the impact of Cadwyn Môn on those who received the service.

Methods: The evaluation adopted a mixed-methods design. Standardised measures of loneliness, social isolation and well-being were obtained at baseline and follow-up time points, and a qualitative element explored client experiences further.

Results: Improvements were observed in all standardised measures. Qualitative interviews also revealed important psychological and lifestyle changes.

Conclusions: Given the anticipated rise in loneliness and social isolation alongside an ageing population, this evaluation contributes to understanding the qualities required for interventions to be effective. The findings provide support for the importance of developing individualised interventions that aim to gradually re-integrate people into their communities.
\end{abstract}

\section{Keywords}

Loneliness, social isolation, well-being, older people, intervention, befriending, volunteer, service 


\section{Introduction}

Cadwyn Môn (translates from Welsh as 'Anglesey Links/Chain’) was a service provided by Age Cymru, Gwynedd and Môn, that aimed to reduce loneliness and isolation of older people living on Anglesey, North Wales. This paper reports an evaluation of the service. Loneliness, defined as a perceived lack of quality relationships, and social isolation, characterized by an absence of ties to others, ${ }^{1}$ are distinct but interconnected concepts. They are linked to negative physical and mental health outcomes such as heart disease, ${ }^{2,3,4}$ depression, ${ }^{3,4}$ poor well-being ${ }^{4}$ and cognitive decline, ${ }^{2,3}$ as well as mortality ${ }^{5}$ in older people. Older adults are particularly vulnerable to loneliness and isolation due to changes in social connections in later life, such as the increased likelihood of bereavement of their spouse or partner and close friends, and living alone. ${ }^{6}$ Loneliness and isolation are a growing concern in the United Kingdom, and have received a surge in attention in recent years, particularly in response to the establishment of the Campaign to End Loneliness, ${ }^{7}$ Jo Cox's Commission on Loneliness, ${ }^{8}$ and the appointment of the first Minister for Loneliness in the UK. ${ }^{9}$ Although the percentage of people over 50 reporting feeling lonely often has remained similar over the last decade in the UK (6-8\%), ${ }^{10}$ more older people are now living longer; thus the quantity of over 50's experiencing loneliness is also anticipated to increase. For example, in England the number is projected to increase from 1.4 million in $2016 / 17$ to 2 million by $2025 / 26{ }^{10}$ In terms of social isolation, recent evidence from Wales found that $27 \%$ of participants over 65 in CAFS Wales (Cognitive Function and Ageing Study) were classed as socially isolated, and those experiencing isolation were more likely to be men, had a poorer cognition, were less educated, and participated in fewer cognitive activities. ${ }^{11}$ 
Given the vulnerability of older adults to loneliness and isolation, their detrimental effects on health, and the projected rise in loneliness to coincide with a growing older population, it is important to address these issues at both clinical and policy levels. The National Institute for Health and Care Excellence (NICE) guidelines around mental wellbeing and independence in older people suggest participation in group, one-to-one and volunteering activities to be helpful. ${ }^{12}$ Group activities may create a sense of security and belonging, ${ }^{13}$ and time spent one-to-one might elicit higher quality bonds between people and empower them to participate socially. ${ }^{2}$

Numerous reviews have explored the effectiveness of different interventions attempting to address loneliness and isolation in older people. Some have reported group interventions to be most effective, ${ }^{14-17}$ and some found more positive findings in one-toone interventions. ${ }^{18,19}$ Others described strengths in both. ${ }^{19,20}$ What is apparent is that there is a lack of consensus in optimal design of interventions targeting loneliness and isolation in older people. Reviews point to a lack in quality of evidence in the literature, and a need for more research. ${ }^{15,16,18,20-22}$

There have however, been recommendations around what aspects of interventions have elicited positive outcomes, particularly in a community setting. Interventions incorporating educational components and social network/group maintenance, ${ }^{2,14,18}$ social activities, ${ }^{15,17}$ adaptability to a local context/utilizing existing community resources, ${ }^{16,20-22}$ support, ${ }^{15,17}$ 'gatekeepers', ${ }^{16,19}$ and targeting specific groups of older people ${ }^{14-16,22,23}$ have been recommended. Moreover, designs that combine a number of approaches (e.g. aspects of education, social and cognitive support via a 'gatekeeper'), ${ }^{18,19}$ or tailoring programmes to meet individual needs, involving older people in planning and 
implementing the intervention, may be more appropriate and successful in decreasing loneliness and social isolation, ${ }^{12,15,16,20,22,23}$ given the individuality of the experience. Indeed, interventions involving people who are trained to individually-tailor interventions to the persons' needs, with the aim of gradually facilitating social participation, have shown promising results. For example, the I-SOCIAL intervention showed lasting reductions in loneliness in the intervention group in a randomized controlled trial. ${ }^{24}$ The Upstream service for socially isolated older people elicited initial quantitative and qualitative improvements in mental well-being and depression, with improvements in perceived social support emerging at 12-month follow-up. ${ }^{25}$ Following on from the Upstream study, the Community Mentoring randomized controlled trial explored the model further, yielding no significant effects on standardized measures ${ }^{26}$ highlighting the need for further research of this type of intervention.

This paper presents the evaluation of Cadwyn Môn, a service designed to alleviate loneliness and isolation in older people. Individuals were matched to a volunteer who worked with them, aiming to bridge the gap between older people and groups and services available in their communities. The aims of the evaluation were to explore the impact of the Cadwyn Môn service on well-being, loneliness, isolation and social participation of those taking part.

\section{The Cadwyn Môn programme}

Cadwyn Môn was a service was led by Age Cymru Gwynedd and Môn. After referral, a local coordinator contacted clients to arrange for a volunteer to meet with them. Beginning on a one-to-one level, the volunteer offered companionship, practical and 
psychological support, to increase social networks, confidence and independence, and over time enable that individual to participate more in their local community. They met once per week, over the course of 10-15 weeks.

The volunteer and client set out subjective goals, tailored to the individuals' barriers and needs. In time, if the individual felt confident to venture out, the volunteer would accompany the individual to existing community support networks, offering the next step, encouraging them to become more independent. Participants were able to access other local services, including Good Turn Schemes, carer and other support groups, over 50s groups, Age Well centres (Age Cymru centres that create social opportunities for older people in North Wales) and more. Additionally, a monthly Cadwyn Môn social club was set up as part of the service, which was open to all referred clients. Some clients were referred directly to this club, if they did not require the assistance of a volunteer.

\section{Methods}

The evaluation adopted a mixed-methods design, obtaining quantitative data from participants before and after they received the service and a qualitative element exploring personal experiences. The service was delivered between 2012 and 2016. The research team met with Age Cymru during the development of the bid to discuss the outcomes of Cadwyn Môn, and how these could be measured. On award of the grant, they met again with the newly recruited coordinators to develop the questionnaires, and advise on interviewing techniques. Cadwyn Môn coordinators collected the data, volunteers set out individualized goals and worked with each client, and researchers at the University provided advice and undertook the analysis. 


\section{Participants}

Clients of the service were provided with information about the evaluation, and if willing to take part, signed a consent form. Evaluative assessments were made by coordinators in face-to-face interviews, both pre- and immediately post-intervention. Age Cymru anonymized participant data before sending to the research team at Bangor University. The project recruited clients through three routes 1) an official referral system for organizations (e.g. social services), 2) self-referral, and 3) referral by family and friends. The inclusion criteria were: age 50+ living on Anglesey, North Wales; at risk of loneliness and isolation due to physical and mental health (depression and anxiety) problems; experience of a recent life event (e.g. bereavement, health deterioration); willing and able to leave the house with assistance (i.e. that is was physically possible to take them out in a car). People with a diagnosis of dementia were excluded from taking part to avoid overlap with other local services. Figure 1 provides referral information and details of those consenting to take part in the evaluation.

\section{[Insert Figure 1 here]}

Figure 1. Flow chart of referrals to Cadwyn Môn, and recruitment to the evaluation.

There were 686 referrals made to the service, with 535 people accepting support (of these, 114 were referred directly to the Cadwyn Môn social club and did not receive the intervention). The service was not conditional on agreeing to provide data, and 182 clients agreed to take part in the evaluation, completing baseline interviews; 62 of which did not complete the programme. Data analysis was performed on the remaining 120 that also completed follow-up assessments. 


\section{Measures}

\section{Quantitative assessment}

Loneliness was measured by the 6-item DeJong Gierveld Loneliness Scale,${ }^{27}$ in which a score of 2 or higher indicates loneliness, and score of 6 indicating severe loneliness. Social isolation/social resources was measured using the Lubben Social Network Scale (LSNS), ${ }^{28}$ comprising of 6 questions evaluating the extent of contact with friends and family. These are summed into a total score between 0 (no contact/extreme social isolation) and 30 (well-connected/not socially isolated). A clinical cut off point of $<12$, is considered at risk of extreme social isolation. Well-being was assessed with the Satisfaction with Life Scale (SWLS) ${ }^{29}$ which asks five questions designed to measure global cognitive judgments of satisfaction with one's life, providing a maximum total score of 35 that fall into 6 categories of satisfaction (Very high [30-35]; High [25-29]; Average [20-24]; Below average [15-19]; Dissatisfied [10-14]; and Extremely dissatisfied [5-9]). The data were coded in accordance with the guidelines of the measures used.

Some further questions ascertained how often clients left the house (scored from 0 [never] - 5 [daily]), for medical visits or to socialize, to understand the extent of isolation pre- and post-intervention.

\section{Data Analysis}

Descriptive statistics were obtained for client demographics. Change over time in loneliness, social isolation and well-being were analyzed using within-subjects repeated measures Analysis of Variance. A Wilcoxon signed rank test was used to analyze the 
frequency of leaving the house data. Analysis was undertaken only on complete cases, with listwise deletion in SPSS (Version 22) removing any cases with missing data.

\section{Qualitative assessment}

At baseline, clients were asked what their support requirements were; during the followup interview, they were given the opportunity to answer a number of open-ended questions exploring their experiences of the Cadwyn Môn programme, including perceptions and expectations of the service and its impact on their lives. All qualitative data were transcribed by a researcher at Bangor University, and an inductive thematic analysis ${ }^{30}$ was performed, with important themes emerging from the data being identified and reported.

\section{Results}

Table 1 outlines the baseline characteristics of the participants. Those who took up the service were mostly female and most lived alone. They often required support after a recent life event, such as bereavement, deterioration in health, or being recently discharged from hospital. At baseline, the majority of clients had limited access to transport; more than three quarters did not drive, most did not use public transport. Mental health issues often reported were depression, anxiety and stress. Physical health concerns included mobility problems, falls, and sensory difficulties, with frailty and being housebound less often reported (note: those identifying themselves as housebound included people with agoraphobia, and people recovering from a recent incident such as stroke). Support requirements given by clients are categorized thematically into six types; 
the most common being assistance/company to go out, help to join a club/class/meet people, to gain confidence/independence, and for company.

\section{[Insert Table 1 here]}

Table 1. Participant characteristics at baseline

\section{Change over time}

Standardized measures of Loneliness, Social isolation and well-being revealed changes between baseline and follow-up time points. Table 2 provides an overview of the results. The Loneliness Scale $^{27}$ revealed a significant decrease in average score from baseline ( $M$ $=3.43, S D=1.94)$ to follow-up $(M=2.49, S D=1.83 ; F(1,113)=39.33, p<.001)$, indicating a reduction in loneliness.

\section{[Insert Table 2 here]}

Table 2. Results of standardized measures of loneliness, social isolation and well-being.

The mean score on the $\mathrm{LSNS}^{28}$ at baseline was low $(M=10.34)$, suggesting limited available social networks and support. There was a significant increase from baseline $(M=10.34, S D=5.09)$ to follow-up score $(M=11.18, S D=4.90 ; F(1,118)=8.45, p=.004)$, indicating increased contact with family and friends.

The SWLS ${ }^{29}$ assessed well-being of clients both before and after the service $(n=115)$, and revealed a significant improvement from baseline $(M=18.99, S D=6.30)$ to follow-up $(M=21.59, S D=5.20 ; F(1,114)=63.59, p<.001)$, indicating improvement to well-being. Two additional questions ascertained how often clients left the house to socialize and attend medical appointments. Table 3 demonstrates the shift in frequency between 
baseline and follow-up (complete data reported). A Wilcoxon signed-rank test showed a statistically significant increase in the frequency that individuals left the house to socialize $(Z=-5.535, p<.001)$, between baseline $(M d n=2)$ and follow-up $(M d n=4)$. There was no change in how often they left the house to attend medical appointments between baseline $(M d n=2)$ and follow-up $(M d n=2 ; Z=-.468, p=.640)$.

\section{[Insert Table 3 here]}

Table 3. Frequency of leaving the house at baseline and follow-up.

\section{Qualitative assessment}

The qualitative component of the follow-up interview was completed by 113 clients; the majority of responses praising the programme, and describing positive experiences of their time with Cadwyn Môn. Figure 2 depicts common themes that emerged from the inductive thematic analysis.

\section{[Insert Figure 2 here]}

Figure 2. Themes emerging from qualitative interviews with participants.

Clients decided to take part in the study primarily for company, to gain confidence, to have more of a social life, and to get out. Consistent with the baseline quantitative measures, many report having been lonely or isolated. Reasons for deciding to engage in the programme included referral to the service by their children or close family; feelings of loneliness and isolation as a result of a recent loss or bereavement; and a number of 
clients had recently had health or mobility problems that had affected their social lives and their confidence.

"I felt very lonely after my husband passed away and found it difficult to go out and felt isolated"

When asked about their experience of taking part in the programme, a main theme that emerged is that of enjoyment, and there were reports of enjoying different aspects such as the company of the volunteer, activities, and going out. The majority of participants reported positive psychological changes in themselves since becoming involved in the programme, with some also reporting improved physical health. Participants said they were more confident, happier and feeling better with a better outlook on life since receiving the service.

"I have changed in the last ten weeks, I am much happier having found some places to go like joining the local WI [Women's Institute] and the local lunch club that I didn't know existed".

Numerous lifestyle effects were also reported by participants. Increased independence was reported, often due to changes in ability to access transport at the end of the programme.

"I can now go on public transport AND book taxis to go places - didn't want to ask them to help me at first but they are really helpful."

Some took up old hobbies, and others learned new skills, such as using the internet to contact people. Re-connecting with old friends, and making new ones were prominent themes. Participants reported making new friends in the classes and groups that they had joined with the assistance of Cadwyn Môn, and others had been able to get in touch and meet up with old friends: 
"My social life has become busy and I have made new friends" Some described finding it difficult to make new friends, but despite this were being more sociable by regularly attending groups, and one person had made new friends but did not wish to attend groups yet.

For many participants, what made the programme work was that the volunteer was wellmatched to the client. The kindness, patience, support and guidance of the volunteers was reassuring and helped increase confidence. In addition to the quality of the volunteers, the fact that Cadwyn Môn refers clients on to other services and groups during the programme was noted as something that adds to its effectiveness. Most clients claimed to be satisfied with the programme and their achievements, with some stating that it exceeded their expectations. Many reported satisfaction in discovering and joining groups or classes in their local area, resulting in new friendships and social connections.

"The key things that make it work is the excellent volunteers and their patience with us. It is also good that they have a goal at the end of the ten weeks and the fact that they can refer people on to others such as the Red Cross or WRVS."

The main criticism of the service was that participants often felt it was too short, and they suggested revising the length of the programme in future. Nevertheless, only five participants report not achieving what they had hoped to, but most reported positive changes despite this: Two reported a greater appreciation of what is important in life and one was going to participate more in their community. One person had a fall during the programme and was unable to continue going to exercise classes, and the other gave no reason.

These results suggest that overall, from the perspective of those who took part, the Cadwyn Môn programme was successful in increasing confidence, and facilitated social connectedness in the community. 


\section{Discussion}

The results of the evaluation showed significant improvements in measures of loneliness ${ }^{27}$ social isolation ${ }^{28}$ and well-being ${ }^{29}$ between baseline and immediately after the Cadwyn Môn intervention. These are supported by qualitative reports of improvements in mental health, such as more confidence, independence, enjoyment, and an improved outlook on life. Other analysis also revealed that participants were leaving the house to socialize more at follow up, supported qualitatively by reports of increased social contact, friendships, and participation in groups/activities in the community. Furthermore, only a small number of participants had not achieved what they had hoped to, suggesting that the needs that had been explicitly given by the clients were met, with benefits that could last beyond the period of the service. Given the association of loneliness and isolation with poor health, and their expected rise to coincide with the ageing population, these findings contribute to an important step forward in understanding effective interventions for older adults.

Social care regulation in Wales ${ }^{31}$ requires local authorities to provide preventive services that enable individuals to live their lives as independently as possible, focusing on identifying the outcomes that the individual wishes to achieve in day-to-day life. The focus of Cadwyn Môn on working with clients to shape individual goals and outcomes not only embeds government instruction, but also may be the mechanism of success. This evaluation supports other studies that have utilized individualized interventions that are tailored to individual barriers and needs, working to identify goals, beginning on a one-to-one basis, with the aim of integrating into a wider social setting. ${ }^{24,25,26}$ One of the key mechanisms of success in the Upstream intervention ${ }^{25}$ was social re-integration of 
people via enjoyable and appropriate activities that maximized opportunities for social interaction. Another similar intervention, I-SOCIAL, had difficulty finding suitable groups within the local community, ${ }^{24}$ which highlights the need for local resources that are available, suitable and accessible in maximizing lasting social opportunities for older people. The qualitative data from Cadwyn Môn indicates that the volunteers harnessed clients confidence and opportunities to visit local clubs. Clients were often not aware of groups and clubs in their communities, and the majority report having joined groups or classes during their time with the volunteer. What Cadwyn Môn adds is the provision of its own 'social club' that had the purpose of promoting and facilitating social participation (as well as support to attend other existing groups and classes). This was available to clients both during and beyond the programme.

Another key to the success of Cadwyn Môn was the careful matching of volunteers to clients. The qualitative evidence reflects the importance of this matching. Volunteers were able to gain the trust of clients before gradually reintroducing them to their local social resources. Other studies have also used trained individuals to assist with social reintegration. For example, the I-SOCIAL study ${ }^{24}$ involved finding ways to overcome barriers to social integration with the assistance of activities counsellors, and elicited significant reductions in loneliness of the intervention group.

A similar study in Devon, Upstream, ${ }^{25}$ focused on social isolation in older people. A mentor worked closely with socially isolated people to facilitate participation in individually-tailored, creative and meaningful social activities while gradually reducing level of support. Qualitative data suggested that they helped build self-confidence and self-efficacy of clients. The results of the service were encouraging and the scheme was 
further investigated as a prospective controlled trial, but found no significant differences in outcome measures between the intervention and control groups. ${ }^{26}$ Although these previous involved provision of trained mentors/counsellors, they do not mention whether or not these individuals were carefully matched to the clients. It seems that a good rapport and finding 'common ground' (be it via background, language, life experience or local knowledge) could be an important aspect for encouraging older people that are experiencing loneliness and isolation to engage with interventions.

The qualitative and quantitative measures used in the Cadwyn Mon evaluation appear to have been appropriate. While the quantitative measures of loneliness, social isolation and well-being provided statistically significant changes, the qualitative aspect elicited interesting additional information about lived experiences during and after the service, and further validated the quantitative outcomes. Other studies have had mixed results utilizing a range of outcome measures. The I-SOCIAL ${ }^{24}$ intervention targeted and measured loneliness, and reported significant reductions by the intervention group postintervention and at 3-month follow-up. The Upstream ${ }^{25}$ and Community Mentoring ${ }^{26}$ trial targeting social isolation in Devon measured health status, social activity and depression. Some encouraging preliminary findings were reported in the first (Upstream, pilot) study, but the second (Community Mentoring, trial) study found no significant changes. They did not utilize measures of loneliness or social networks/isolation. Careful consideration of quantitative outcome measures may have produced different results for this scheme. On the other hand, we accept that had Cadwyn Môn been run as a trial, this may have also led to different findings. 


\section{Limitations and future suggestions}

The evaluation of Cadwyn Môn produced encouraging outcomes, but there are some issues to consider for future work. Firstly, despite there being significant improvements in all measures, the mean score at follow-up for loneliness was above 2, thus still considered lonely, and the mean score of LSNS was still below the clinical cut-off point of $<12$, indicating isolation. This may reflect a need for the service to be amenable to longer time periods in order to observe more extensive change. The most consistent comment regarding areas of improvement for the service was that it was not long enough, and others have found this too. ${ }^{24} \mathrm{~A}$ future suggestion may be to not only tailor the intervention itself, but to also to tailor its length, according to the persons' needs. Data were collected during interviews with coordinators, which may have led to bias in reporting, particularly in the qualitative component. It is possible that participants would wish to please the interviewer, given that they were connected to the project. Future work should consider using independent interviewers for data collection. Unfortunately, this was beyond the budget for the evaluation. It has been suggested that for successful recruitment and retention of older adults in research, one must maximize the benefit:burden ratio of taking part. ${ }^{32}$ Thus to maximize the willingness of people to participate, assurance that all data collection is by a third party, anonymous and not timeconsuming, may be beneficial.

Complete data (i.e. baseline and follow-up) were obtained for $28.5 \%$ (120 of 421) of clients who were referred to the service, which may not give an accurate representation of the effects on a wider range of people. Not all older people will have been equally willing and able to participate in the evaluation, nor to accept support. It is possible that those 
who were willing to participate in the evaluation could have been more ready and willing to engage with the intervention.

The majority of participants in this study were female, whereas recent work from CFAS Wales found that men were more likely to be socially isolated, ${ }^{11}$ raising the question of whether Cadwyn Môn was reaching those who needed it most. Similarly, it was a requirement that it would be possible for the volunteers to take clients out, which means that those who are physically housebound were not able to take part. Future work must attempt to identify and engage those that are hardest to reach.

It must also be acknowledged that clients that did not provide follow-up data for whatever reason may have influenced the overall effects of each measure, particularly due to the fact that there was no control group in this study. Also, although we would hope that the by the nature of the Cadwyn Môn service that it would have effects lasting beyond the period of the service, there is no evidence to support this because follow-up data were collected immediately post-intervention. Future work might consider exploring this programme as a trial including a control group and assessments at 6-months and 12months post-intervention. As there are ethical considerations regarding the allocation of lonely and isolated people to control conditions, the type of control group would need to be carefully considered (e.g. a waiting list control group), to ensure all lonely and isolated people could potentially benefit from the service. An economic analysis may add further insights around the cost of the intervention and its effectiveness.

\section{Conclusion}

The individually-tailored Cadwyn Môn programme may be an effective means of reducing loneliness and isolation, by gradually re-integrating older people into their 
communities. Improvements in confidence, social-life and independence emerged as prominent themes expressed in interviews with clients, further supporting the benefits of the programme. As this was a service evaluation, future work may wish to explore the effectiveness of this type of intervention using more a more rigid experimental research design, such as a randomized controlled trial.

\section{Acknowledgements}

The authors thank Age Cymru, Gwynedd and Mon for providing clients with both quantitative and qualitative measures. With thanks also to the Big Lottery, who funded this project for 5 years. The final report, written for a lay audience, is available at: https://www.owensutton.com/cadwyn-mon-eng/files/assets/basic-html/page1.html

\section{Declaration of Conflicting Interests}

Age Cymru Gwynedd a Môn commissioned the evaluation of this service by the authors.

\section{Funding}

This work was supported by a grant from the Big Lottery, awarded to Age Cymru, Gwynedd a Môn.

\section{Ethical approval}

This was a service evaluation, with the authors being consultants involved in advising and analysing, and thus under HRA guidance it did not require a REC review. 


\section{References}

1 De Jong Gierveld, J., Van Tilburg, T. G., \& Dykstra, P. A. (2006). Loneliness and Social Isolation. In D. Perlman \& A. L. Vangelisti (Eds.), The Cambridge Handbook of Personal Relationships. Cambridge, New York: Cambridge University Press.

2 Nicholson, N. R. A review of social isolation: an important but underassessed condition in older adults. The journal of primary prevention, 2012; 33(2-3): 137152.

3 Smith, K. J., \& Victor, C. Typologies of loneliness, living alone and social isolation, and their associations with physical and mental health. Ageing \& Society, 2018; 1-22.

4 Courtin, E., \& Knapp, M. Social isolation, loneliness and health in old age: a scoping review. Health \& social care in the community, 2017; 25(3): 799-812.

5 Holt-Lunstad, J., Smith, T. B., Baker, M., Harris, T., \& Stephenson, D. Loneliness and social isolation as risk factors for mortality: a meta-analytic review. Perspectives on Psychological Science, 2015; 10(2): 227-237.

6 ONS 2015 Measuring National Well-being: Insights into Loneliness, Older People and Well-being, 2015.

7 Campaign to End Loneliness. Safeguarding the Convoy: A call to action from the Campaign to End Loneliness. Age UK Oxfordshire 2011. Available at: http://www.campaigntoendloneliness.org/ (accessed 19 September 2018) 
8 Cox, J. Commission on Loneliness: a call to action. Report, Jo Cox Commission on Loneliness Dec 15, 2017. https://www.ageuk.org.uk/ourimpact/campaigning/jo-cox-commission/ (accessed 21 September 2018).

9 Prime Minister's Office. Press release: PM commits to government-wide drive to tackle loneliness. https://www.gov.uk/government/news/pm-commits-

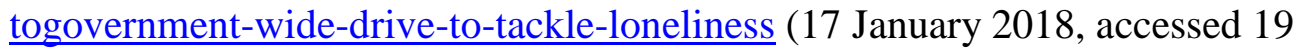
September 2018).

10 Age UK. All the Lonely People: Loneliness in Later Life Technical Report: presentation of analytical methodology and results. https://www.ageuk.org.uk/globalassets/age-uk/documents/reports-andpublications/reports-and-briefings/loneliness/180917_loneliness-report-technicalreport final.pdf (accessed 25 June 2019)

11 Evans, I. E., Llewellyn, D. J., Matthews, F. E., Woods, R. T., Brayne, C., Clare, L., \& CFAS-Wales research team. (2018). Social isolation, cognitive reserve, and cognition in healthy older people. PloS one, 13(8).

12 National Institute for Health and Care Excellence. Mental well-being and independence for older people. Quality standard [QS137]. 2016. https://www.nice.org.uk/guidance/qs137 (accessed 15 September 2018)

13 Masi, C. M., Chen, H-Y., Hawkley, L. C., \& Cacioppo, J. T. A meta-analysis of interventions to reduce loneliness. Personality \& Social Psychology Review, 2011; 15: $219-266$. 
14 Cattan, M., White, M., Bond, J., \& Learmouth, A. Preventing social isolation and loneliness among older people: A systematic review of health promotion interventions. Ageing and Society, 2005; 25(1): 41-67.

15 Dickens, A. P., Richards, S. H., Greaves, C. J., \& Campbell, J. L. Interventions targeting social isolation in older people: a systematic review. BMC public health, 2011; 11(1): 647.

16 Findlay, R. Interventions to reduce social isolation amongst older people: Where is the evidence? Ageing and Society, 2003; 23(5): 647-658.

17 Franck, L., Molyneux, N., \& Parkinson, L. Systematic review of interventions addressing social isolation and depression in aged care clients. Quality of Life Research, 2016; 25(6): 1395-1407.

18 Cohen-Mansfield J., \& Perach R. Interventions for alleviating loneliness among older persons: a critical review. Am J Health Promot, 2015; 29(3): 109-25.

19 Poscia, A., Stojanovic, J., La Milia, D. I., Duplaga, M., Grysztar, M., Moscato, U., Onder, G., Collamati, A., Ricciardi, W., \& Magnavita, N. Interventions targeting loneliness and social isolation among the older people: an update systematic review. Experimental gerontology, 2018; 102: 133-144. 
20 Gardiner, C., Geldenhuys, G., \& Gott, M. Interventions to reduce social isolation and loneliness among older people: an integrative review. Health \& social care in the community, 2018; 26(2): 147-157.

21 Hagan, R., Manktelow, R., Taylor, B. J. \& mallet, J. Reducing loneliness amongst older people: a systematic search and narrative review. Aging \& Mental Health, 2014; $1-11$.

22 Stojanovic, J., Collamati, A., Mariusz, D., Onder, G., La Milia, D. I., Ricciardi, W., Moscato, U., Magnavita, N. \& Poscia, A. Decreasing loneliness and social isolation among the older people: systematic search and narrative review. Epidemiology, biostatistics and public health, 2017; 14(2).

23 Grenade, L. and Boldy, D. Social isolation and loneliness among older people: issues and future challenges in community and residential settings. Australian Health Review, 2008; 32(3): 468-78

24 Cohen-Mansfield, J., Hazan, H., Lerman, Y., Shalom, V., Birkenfeld, S., \& Cohen, R. (2018). Efficacy of the I-SOCIAL intervention for loneliness in old age: Lessons from a randomized controlled trial. Journal of psychiatric research, 99, 69-75. 
25 Greaves, C. J., \& Farbus, L. Effects of creative and social activity on the health and well-being of socially isolated older people: outcomes from a multi-method observational study. The journal of the Royal Society for the Promotion of Health, 2006; 126(3): 134-142.

26 Dickens, A. P., Richards, S. H., Hawton, A., Taylor, R. S., Greaves, C. J., Green, C., Edwards, R. \& Campbell, J. L. An evaluation of the effectiveness of a community mentoring service for socially isolated older people: a controlled trial. BMC Public Health, 2011; 11(1), 218.

27 de Jong Gierveld, J. D. J., \& Van Tilburg, T. A 6-item scale for overall, emotional, and social loneliness confirmatory tests on survey data. Research on Aging, 2006; 28(5): 582-598.

28 Lubben, J., Blozik, E., Gillmann, G., Iliffe, S., von Renteln Kruse, W., Beck, J. C., \& Stuck, A. E. Performance of an abbreviated version of the Lubben Social Network Scale among three European community-dwelling older adult populations. The Gerontologist, 2006; 46(4): 503-513.

29 Diener, E. D., Emmons, R. A., Larsen, R. J., \& Griffin, S. The satisfaction with life scale. Journal of personality assessment, 1985; 49(1): 71-75.

30 Braun, V., \& Clarke, V. Using thematic analysis in psychology. Qualitative research in psychology, 2006; 3(2), 77-101. 
31 Welsh Government. Social Services and Well-being (Wales) Act 2014, http://www.legislation.gov.uk/anaw/2014/4/pdfs/anaw_20140004_en.pdf (2014, accessed 12 February 2019).

32 Mody, L., Miller, D. K., McGloin, J. M., Freeman, M., Marcantonio, E. R., Magaziner, J., \& Studenski, S. (2008). Recruitment and Retention of Older Adults in Aging Research: (See editorial comments by Dr. Stephanie Studenski, pp 2351-2352). Journal of the American Geriatrics Society, 56(12), 2340-2348. 
Table 1. Participant characteristics at baseline

\begin{tabular}{|c|c|}
\hline Baseline characteristics & $\mathrm{N}(\%)$ \\
\hline Male & $22(18.3)$ \\
\hline Female & $98(81.7)$ \\
\hline Age (mean) & 76.7 \\
\hline \multicolumn{2}{|l|}{ Age groups } \\
\hline $50-65$ & $23(19.2)$ \\
\hline $66-85$ & $70(58.3)$ \\
\hline $86-106$ & $27(22.5)$ \\
\hline \multicolumn{2}{|l|}{ Living arrangement } \\
\hline Live alone & $88(73.3)$ \\
\hline Live with others & $32(26.7)$ \\
\hline \multicolumn{2}{|l|}{ Physical Health Issues* } \\
\hline Mobility problems & $66(55)$ \\
\hline Falls/dizziness & $44(36.7)$ \\
\hline Sensory impairment & $50(41.7)$ \\
\hline Housebound** & $9(7.5)$ \\
\hline Frail & $9(7.5)$ \\
\hline \multicolumn{2}{|l|}{ Mental Health Issues* } \\
\hline Anxiety & $56(46.7)$ \\
\hline Depression & $50(41.7)$ \\
\hline Stress & $45(37.5)$ \\
\hline Memory problems & $28(23.3)$ \\
\hline \multicolumn{2}{|l|}{ Life Events* } \\
\hline Health deterioration & $62(51.7)$ \\
\hline Hospital discharge & $21(17.4)$ \\
\hline Bereavement & $25(20.8)$ \\
\hline New to area & $8(6.7)$ \\
\hline Family moving away & $6(5.0)$ \\
\hline Relationship breakdown & $1(0.8)$ \\
\hline \multicolumn{2}{|l|}{ Access to transport } \\
\hline Do not drive & 95 (79.2) \\
\hline Never travel by public bus & $78(65.0)$ \\
\hline \multicolumn{2}{|l|}{ IT and Connectivity } \\
\hline No use of Computer at home & $100(83.3)$ \\
\hline \multicolumn{2}{|l|}{ Support required } \\
\hline Assistance/company to go out & $28(23.3)$ \\
\hline Help to join a club/class/meet people & 35 (29.2) \\
\hline To gain confidence/independence & $30(25)$ \\
\hline For company & $18(15.0)$ \\
\hline Support with mental or physical health needs & $8(6.7)$ \\
\hline Support with care needs & $1(0.8)$ \\
\hline
\end{tabular}

* Multiple options could be selected

** Those identifying themselves as 'housebound' had to be willing/able to get out of the house with assistance of a volunteer. 
Table 2. Results of standardized measures of loneliness, social isolation and well-being.

\begin{tabular}{|c|c|c|c|c|c|c|c|c|}
\hline & & Bas & eline & Follc & w-up & & & \\
\hline Construct & Measure & Mean & Std Dev & Mean & Std Dev & Sig. & $\mathrm{N}$ & $\begin{array}{c}\text { Missing } \\
\text { data }\end{array}$ \\
\hline Loneliness & $\begin{array}{l}\text { De Jong Gierveld } \\
\text { Loneliness Scale }\end{array}$ & 3.43 & 1.94 & 2.49 & 1.83 & $p<.001$ & 114 & 6 \\
\hline Social isolation & $\begin{array}{l}\text { Lubben Social } \\
\text { Network Scale }\end{array}$ & 10.34 & 5.05 & 11.18 & 4.9 & $p=.004$ & 119 & 1 \\
\hline Well-being & $\begin{array}{l}\text { Satisfaction with } \\
\text { Life Scale }\end{array}$ & 18.99 & 6.3 & 21.59 & 5.2 & $p<.001$ & 115 & 5 \\
\hline
\end{tabular}


Table 3. Frequency of leaving the house at baseline and follow up.

\begin{tabular}{lcccc}
\hline & \multicolumn{2}{c}{ To socialise } & \multicolumn{2}{c}{ For medical appointments } \\
& Baseline (N [\%]) & Follow up (N [\%]) & Baseline (N [\%]) & Follow up (N [\%]) \\
\hline Daily & $3[5.3]$ & $6[10.5]$ & $0[0]$ & $0[0]$ \\
2-3 times a week & $9[15.8]$ & $25[43.9]$ & $4[7.0]$ & $3[5.3]$ \\
At least weekly & $12[15.8]$ & $21[36.8]$ & $7[12.3]$ & $9[15.8]$ \\
At least monthly & $7[12.3]$ & $4[7.0]$ & $29[50.9]$ & $29[50.9]$ \\
Less than monthly & $9[15.8]$ & $1[1.8]$ & $14[24.6]$ & $15[26.3]$ \\
Never & $17[29.8]$ & $0[0]$ & $3[5.3]$ & $1[1.8]$ \\
\hline Total N & 57 & 57 & 57 & 57 \\
\hline
\end{tabular}




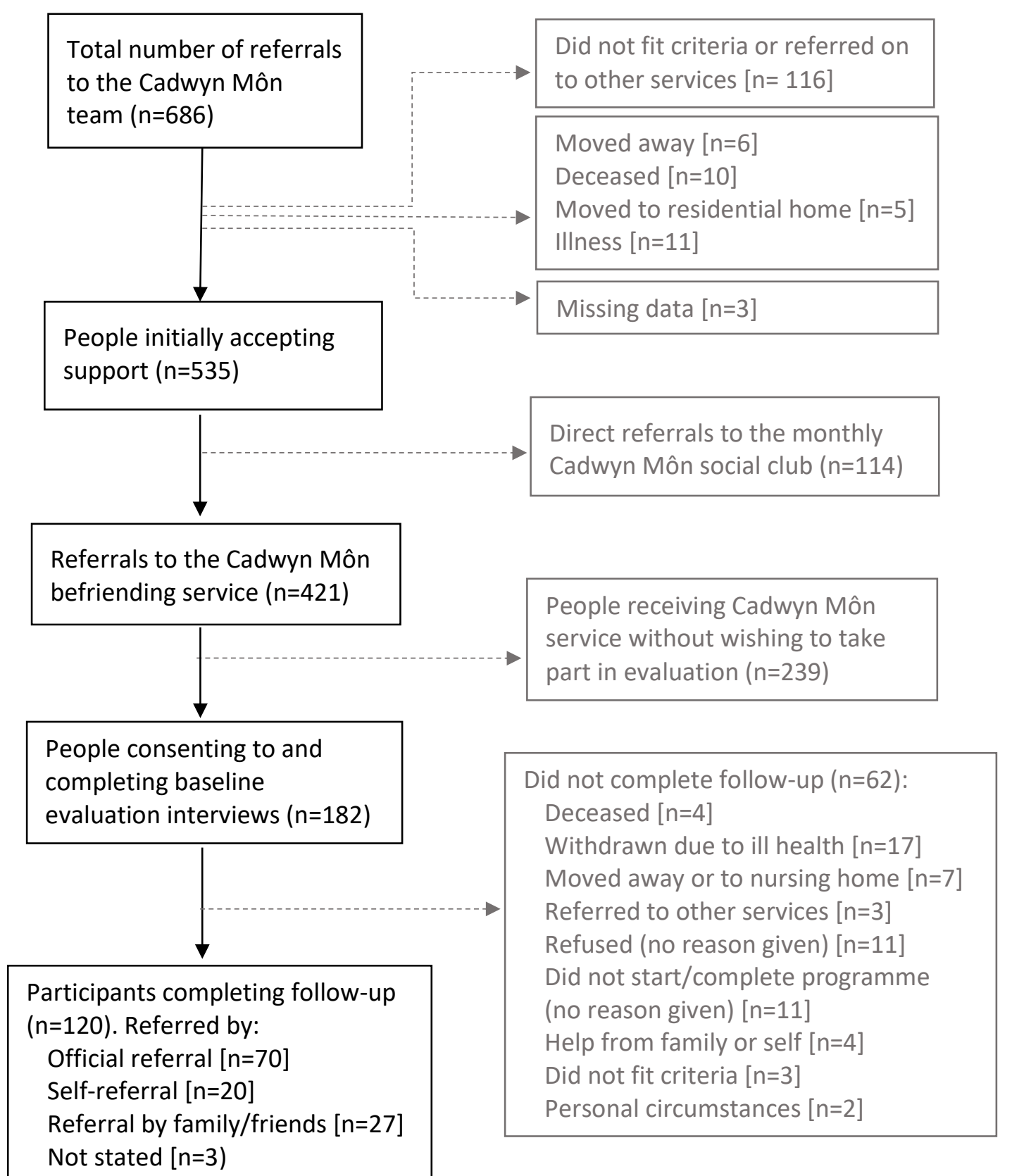

Figure 1. Flow chart of referrals to Cadwyn Môn, and recruitment to the evaluation. 


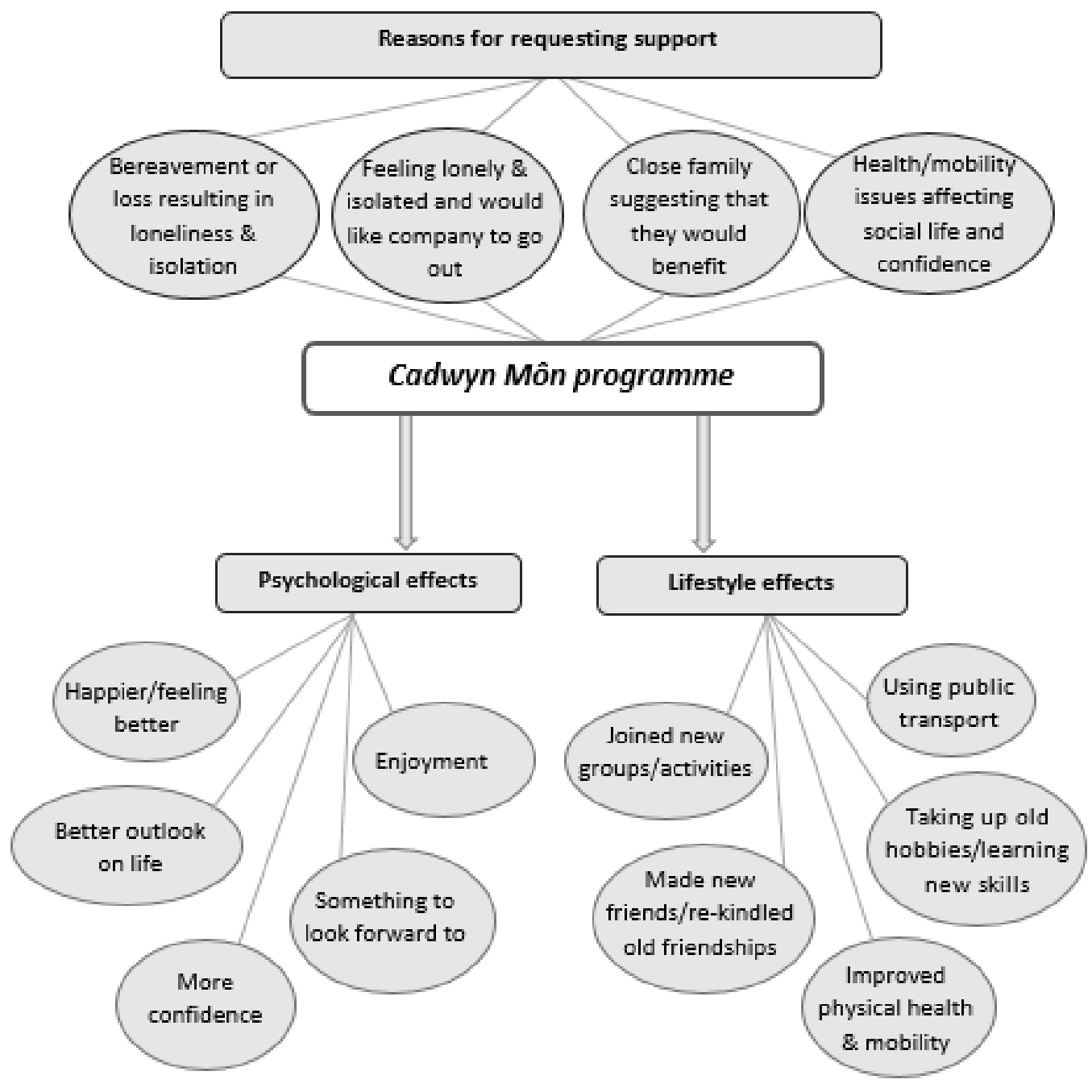

Figure 2. Themes emerging from qualitative interviews with participants. 